\title{
Numerical study of the plastic behaviour in tension of welds in high strength steels
}

\author{
D.M. Rodrigues*, L.F. Menezes, A. Loureiro, J.V. Fernandes \\ Mechanical Engineering Departement (CEMUC), University of Coimbra, Pinhal de Marrocos, \\ 3030 Coimbra, Portugal
}

Received in final revised form 7 August 2002

\begin{abstract}
The influence of the mismatch between material properties and constraint on the plastic deformation behaviour of the heat affected zone of welds in high strength steels is investigated in this study, using finite element simulations. An elastoplastic implicit three-dimensional finite element code (EPIM3D) was used in the analysis. The paper presents the mechanical model of the code and the methodology used for the numerical simulation of the tensile test of welded joints. Numerical results of the tensile test of welded samples with different hypothetical widths for the Heat Affected Zone and various material mismatch levels are shown. The analysis concerns the overall strength and ductility of the joint and in relation to the plastic behaviour of the heat affected zone. The influence of the yield stress, tensile strength and constraint on the stress and plastic strain distribution in the soft heat affected zone is also discussed.
\end{abstract}

(C) 2002 Elsevier Ltd. All rights reserved.

Keywords: A. Ductility; B. Elastic-plastic material; B. Welds; C. Finite elements; C. Mechanical testing

\section{Introduction}

The analysis of a weld produced with a fusion process allows us to distinguish three main zones, usually referred to as the weld metal (WM), the heat affected zone (HAZ) and the base metal (BM). While the first two zones result from the welding process and thermal phenomena associated with it, the BM is the part of the parent plate, not affected by the heat input. In a defect free weld, global mechanical behaviour

\footnotetext{
* Corresponding author. Fax: +351-239-790701.

E-mail address: dulce.rodrigues@dem.uc.pt (D.M. Rodrigues).
} 
depends on the mismatch in mechanical properties between the different welded zones, its dimension and loading mode (Denys, 1994; Dexter, 1997).

To ensure good tensile performance of the joints, manufacturers use a welding metal overmatch approach, i.e., the filler material is selected on the basis that the yield stress of the weld metal must be above that of the base material. However, when the overmatching requirement is achieved, a soft structure can appear in the HAZ. The mechanical properties in this zone can drastically differ from the unaffected base metal depending on the heating and cooling conditions imposed by the welding process and on the structure and chemical composition of the base plate (Easterling, 1985; Soboyejo et al., 2001). This is current in high strength steels for which slow cooling rates can cause a considerable loss in the value of the yield strength of the base plate (Akselsen et al., 1989; Thaulow et al., 1994; Thaulow and Toyoda, 1997; Wojnowski et al., 2000).

High strength steels have found widespread application as a result of their good mechanical properties and service behaviour (Rapacki, 1985; Kinsey, 2000, Yoshida et al., 2002, Cleveland and Ghosh, 2002). Fig. 1 shows a tensile sample of a weld in a quenched and tempered high strength steel where the various constitutive zones are visible. When this type of welded sample is loaded in tension normal to the weld axis, the yield stress mismatch does not affect the deformation behaviour of the joint in the elastic loading range. However, when the joint is plastically deformed, the metal with the lowest value of the yield stress controls the load-elongation behaviour (Dexter, 1997). A typical case of plastic localisation in the HAZ during deformation in tension is shown in the small detail of Fig. 1.

In this context, it is important to determine the influence of the presence of a soft material on the overall mechanical behaviour of the joint. However, the experimental analysis of the stress-strain distribution in a welded joint is a very difficult task. Indeed, the non-linearities involved in the process, such as the different elastoplastic behaviour of the various welded zones, its geometries, the non-homogeneous strain and stress distribution makes all possible experimental analysis very complicated. Using numerical simulation, it is possible to analyse individually the

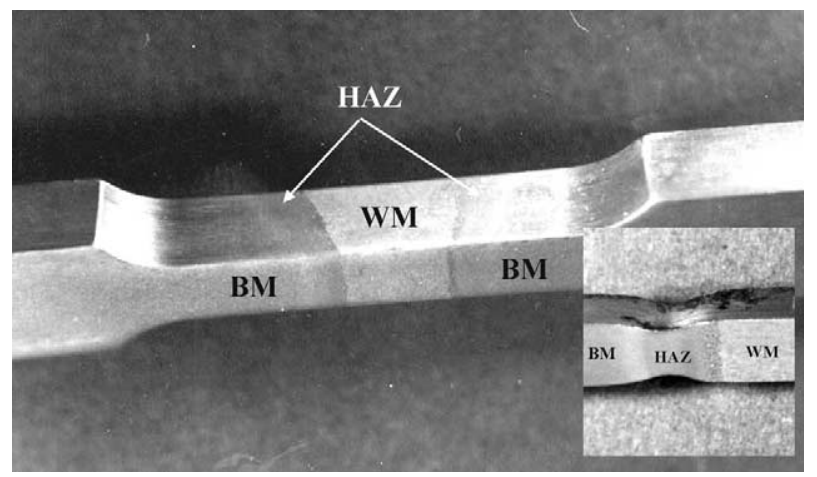

Fig. 1. Tensile sample enhancing the various constitutive zones. The small detail in the picture shows the plastic localisation in the HAZ after deformation in tension. 
various phenomena that occur in a tensile test of a welded joint. In fact, in our days, numerical simulation have become a very important tool to clarify and confirm experimental observations, and even to establish detailed conclusions on the mechanical behaviour of all types composite materials (Marketz et al., 2003; Goda, 2002, Saraev and Schmauder, 2003).

The main purpose of this work is to evaluate the influence of the degree of the mismatch of material properties and the size of the HAZ on the plastic behaviour observed in tension of defect free welded plates. The local and overall plastic behaviour of the joint is studied by modelling an arbitrarily chosen material for the HAZ and progressively changing the width of this zone. The influence of the material mismatch is studied simulating various hypothetical materials for the same HAZ dimensions. The numerical simulations were performed with the code EPIM3D, a FEM home code developed to solve problems that involve large elastoplastic transformations. The code makes use of a full implicit constitutive time integration operator, and 3-D trilinear isoparametric elements associated with a selective reduced integration technique (Menezes et al., 1991, 1999).

\section{Procedure}

In order to determine the influence of the mismatch in material properties in the plastic deformation behaviour of the welded joints, several numerical simulations of the tensile test were performed. Finite element meshes with three different material domains that represent the WM, BM and HAZ were used. The different weld zones are assumed to have an isotropic elastoplastic behaviour with isotropic work-hardening described by the Swift equation:

$$
Y\left(\bar{\varepsilon}^{\mathrm{p}}\right)=C\left(\varepsilon_{0}+\bar{\varepsilon}^{\mathrm{p}}\right)^{n}
$$

where $Y$ is the flow stress in simple tension, $\bar{\varepsilon}^{\mathrm{p}}$ is the equivalent plastic strain, $n$ the hardening coefficient and $C$ and $\varepsilon_{0}$ are material constants.

In order to cover a large range of mismatch conditions, simulations were performed using various hypothetical values for the yield stress $\left(Y_{0}=C \varepsilon_{0}^{n}\right)$ and for the hardening parameter $(n)$ of the HAZ material. These mechanical properties must be intended as mean properties, since various types of metallurgical structures with different mechanical properties are present along the HAZ. In the absence of defects, this assumption simplifies the mechanical model without compromising de validity of the conclusions of the present study. For the WM and BM the same high strength mechanical properties were considered, representing an evenmatch joint with 700 MPa yield stress and hardening coefficient, $n=0.08$. Table 1 summarises the mechanical properties of the HAZ and the values of yield stress mismatch $\left(M_{\mathrm{YS}}=Y_{0}^{\mathrm{HAZ}} / Y_{0}^{\mathrm{ADJ}}\right)$ and tensile strength mismatch $\left(M_{\mathrm{TS}}=Y_{\max }^{\mathrm{HAZ}} / Y_{\max }^{\mathrm{ADJ}}\right)$ relative to the adjacent materials (WM and BM) studied in this work. In this text the term undermatching is used when the mismatch parameters $M<1$, evenmatch when $M \cong 1$ and overmatching when $M>1$. 
Table 1

Material properties and stress mismatch ratios: Yield mismatch $\left(M_{\mathrm{YS}}=Y_{0}^{\mathrm{HAZ}} / Y_{0}^{\mathrm{ADJ}}\right)$ and tensile strength mismatch $\left(M_{\mathrm{TS}}=Y_{\mathrm{TS}}^{\mathrm{HAZ}} / Y_{\mathrm{TS}}^{\mathrm{ADJ}}\right)$

\begin{tabular}{lllllll}
\hline \multirow{2}{*}{$\begin{array}{l}\text { MPa }) \\
Y_{0}^{\mathrm{HAZ}}\end{array}$} & $M_{\mathrm{YS}}$ & $(0.08)$ & $(0.1)$ & $(0.12)$ & $(0.14)$ & $(0.16)$ \\
\hline 400 & 0.57 & 0.65 & 0.71 & 0.79 & 0.88 & 0.98 \\
500 & 0.71 & 0.81 & 0.89 & 0.99 & 1.10 & 1.23 \\
600 & 0.86 & 0.97 & 1.07 & 1.19 & - & - \\
\hline
\end{tabular}

Fig. 2 presents the stress-strain curves that correspond to Eq (1), for the various HAZ materials studied. Observing these curves, it is possible to perform an analysis of the mechanical behaviour of the materials of the joints. For example, for the HAZ material with $400 \mathrm{MPa}$ yield stress, the figure indicates yield and tensile strength undermatch $\left(M_{\mathrm{YS}}\right.$ and $M_{\mathrm{TS}}<1$, see Table 1$)$ for all the hardening values, except $n=0.16$ that presents tensile strength evenmatch $\left(\mathrm{M}_{\mathrm{TS}} \cong 1\right)$. For the hardening values $0.08,0.10$ and 0.12 the maximum load of the HAZ material is lower then the yield stress of the adjacent materials, but, for $n=0.14$ and 0.16 yielding of the adjacent materials must occur before the maximum load is reached in the HAZ material.

When the HAZ materials have 500 and $600 \mathrm{MPa}$ yield stresses, yielding of the adjacent materials is possible in all situations, except for $Y_{0}=500 \mathrm{MPa}$ with $n=0.08$. For $\left(Y_{0}=500 \mathrm{MPa}, n=0.14\right.$ and 0.16$)$ and $\left(Y_{0}=600 \mathrm{MPa}, n=0.10\right.$ and 0.12$)$ the maximum load is lowest for the WM and BM presenting tensile strength overmatch in the HAZ $\left(M_{\mathrm{TS}}>1\right)$. It is still important to enhance the materials $\left(Y_{0}=400 \mathrm{MPa}\right.$, $n=0.16),\left(Y_{0}=500 \mathrm{MPa}, n=0.12\right)$ and $\left(\mathrm{Y}_{0}=600 \mathrm{MPa}, n=0.08\right)$ that represent the tensile strength evenmatch situations $\left(M_{\mathrm{TS}} \cong 1\right)$.

In order to regard the influence of the HAZ size in the geometrical constraint effect, and consequently, in the mechanical behaviour of the joint, various HAZ widths $\left(l_{\mathrm{HAZ}}\right)$ were represented in the finite element meshes used in the numerical simulations. These meshes represent samples with a square cross section $\left(6.125 \times 6.125 \mathrm{~mm}^{2}\right)$, which were used in experimental studies (Rodrigues et al., $1999)$. As the ratio width of the softened zone to plate thickness $\left(l_{\mathrm{HAZ}} / e\right)$ is an important parameter characterising the change of strength in the joint, in the present study it covers the range $1 / 6-1$. Table 2 shows the various HAZ widths studied in the present work.

Table 2

$\mathrm{HAZ}$ widths used in the numerical simulations

\begin{tabular}{llc}
\hline Specimen designation & $l_{\mathrm{HAZ}}(\mathrm{mm})$ & $l_{\mathrm{HAZ}} / e$ \\
\hline HAZL1 & 1 & $1 / 6$ \\
HAZL2 & 2 & $1 / 3$ \\
HAZL4 & 4 & $2 / 3$ \\
HAZL6 & 6 & 1 \\
\hline
\end{tabular}





Fig. 2. Stress-strain curves corresponding to the mechanical behaviour of the various welding zones. In each graph, the grey curve corresponds to the mechanical behaviour of the adjacent materials (BM and WM) and the black curves represent hypothetical conditions studied for HAZ materials. 


\section{Finite element analysis}

\subsection{Material modelling}

The 3-D finite element code EPIM3D (Elasto Plastic Implicit 3D finite element code) is devoted to the numerical simulation of large plastic deformation processes (Menezes et al., 1991, 1999). The mechanical model is based on the elastoplastic behaviour of the materials with isotropic and kinematic work hardening. To describe the elastic behaviour of the material, the hypoelastic form of Hooke's law that is valid for arbitrary large rotations is used. The plastic behaviour of the materials is described by the general quadratic yield condition

$$
f(\bar{\sigma}, h)=\bar{\sigma}-h=0
$$

with an associated inviscid flow rule. In Eqs (2) $\bar{\sigma}$ is Hill's equivalent stress that in the absence of kinematic work-hardening is defined by the quadratic form:

$$
\begin{aligned}
\bar{\sigma}^{2}= & F\left(\sigma_{22}-\sigma_{33}\right)^{2}+G\left(\sigma_{33}-\sigma_{11}\right)^{2}+H\left(\sigma_{11}-\sigma_{22}\right)^{2}+2 L \sigma_{23}^{2}+2 M \sigma_{13}^{2} \\
& +2 N \sigma_{12}^{2}
\end{aligned}
$$

where $F, G, H, L, M$, and $N$ are material constants. $h$ is the flow stress which evolution with progressive deformation can be described by the isotropic workhardening Swift law [Eq. (1)], by the modified Swift law for prestrained materials (Fernandes et al., 1998) or by the Teodosiu law valid for anisotropic work-hardening under arbitrary strain-path changes at moderately large strains (Teodosiu and $\mathrm{Hu}, 1995$; Hiwatashi et al., 1998; Li et al., 2003). In this study, the mechanical behaviour of the materials was considered isotropic by setting $F=G=H=0.5$ and $L=M=N=1.5$ and the work-hardening is simply described by Eq. (1).

\subsection{Finite element discretization}

Fig. 3 shows the finite element meshes used in the simulations detailing the different material regions and widths. The finite element discretization makes use of the eight-node hexahedron isoparametric element with selective reduced integration. This element is the most commonly used in this type of problem and has a good compromise accuracy/CPU time if a correct integration scheme is used. Only $1 / 8$ of the sample was simulated, considering geometrical and material symmetry relative to the axes $O x, O y$ and $O z$. The interfaces between the different material regions of the welded joint are planar and normal to the longitudinal axis of the sample. The boundary conditions used in the simulations are also schematised in Fig. 3. For simplicity the sample is represented in the $O x y$ plane. The tensile test is simulated by imposing positive displacements on the $O x$ direction in the nodes located on the $x=L / 2$ plane.

In Fig. 4 a three dimensional representation of one of the finite element meshes used in this study is shown. In this figure, $a$ and $b$ represent lines in the sample surface for which the stress and strain distribution will be plotted later in this analysis. 


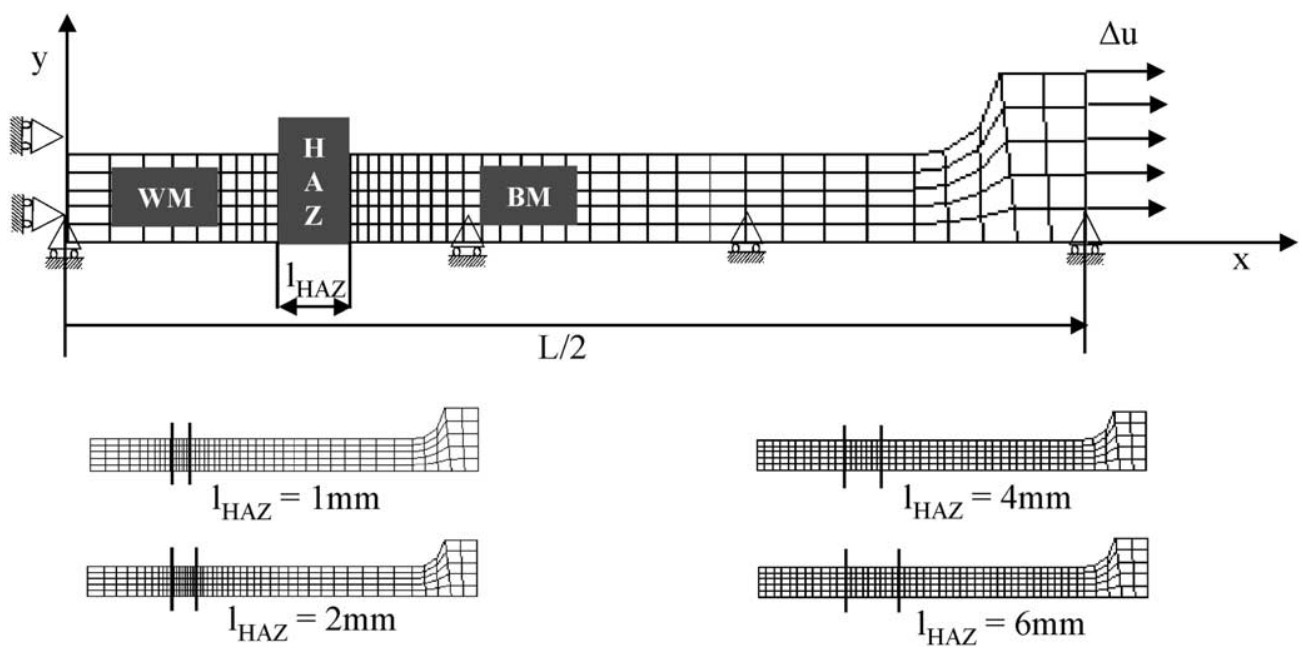

Fig. 3. Boundary conditions and different types of meshes used in the tensile test simulations.

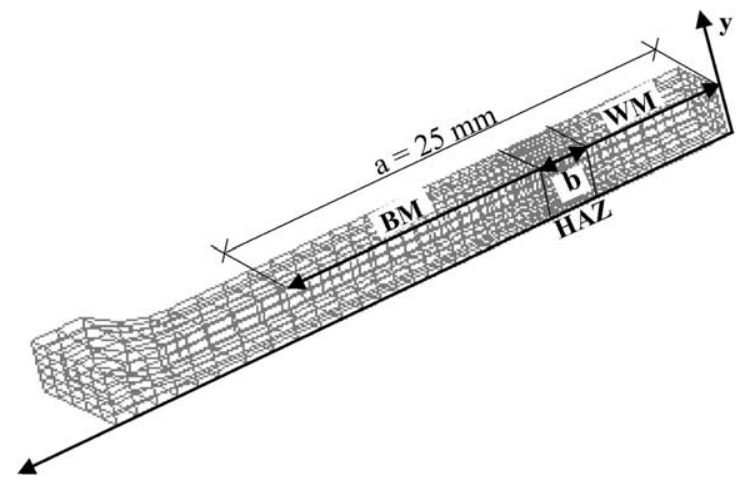

Fig. 4. Three-dimensional finite element mesh of the sample HAZL4.

\section{Results and discussion}

\subsection{Strength and ductility of the overall sample}

In Fig. 5, the numerical results of the maximum load attained by the various types of tensile samples $\left(F_{\text {joint }}\right)$, normalised with the maximum load attained in a tensile test of homogeneous base plate sample $\left(F_{\text {hom }}\right)$ are shown. The results are grouped according to the different yield stress values and HAZ widths and are plotted relative to the tensile strength mismatch $\left(M_{\mathrm{TS}}\right)$.

The results presented in Fig. 5 enable an analysis of the strength loss of the joint relative to the base plate. For all the samples with HAZ overmatch tensile strength $\left(M_{\mathrm{TS}}>1\right)$ no loss in strength relative to the homogeneous base plate occurs $\left(F_{\text {joint }} /\right.$ $\left.F_{\text {hom }} \cong 1\right)$. To explain these results, the equivalent stress distribution for a sample 


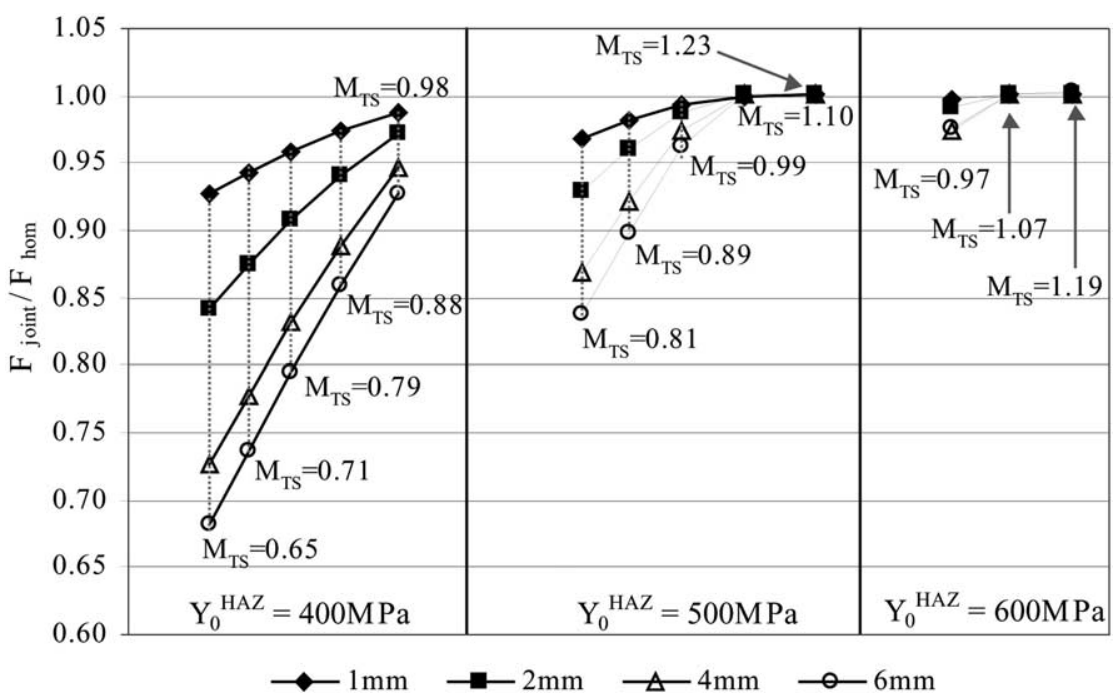

Fig. 5. Normalised load values $\left(F_{\text {joint }} / F_{\text {hom }}\right)$ as a function of the tensile strength mismatch $\left(M_{\mathrm{TS}}\right)$, for different $\mathrm{HAZ}$ yield stresses $\left(Y_{0}^{\mathrm{HAZ}}=400,500\right.$ and $\left.600 \mathrm{MPa}\right)$ and $\mathrm{HAZ}$ widths $\left(l_{\mathrm{HAZ}}=1,2,4 \mathrm{and} 6 \mathrm{~mm}\right)$.

with HAZ tensile strength overmatch material $\left(Y_{0}=500 \mathrm{MPa}, n=0.16\right)$ is plotted, in Fig. 6, along a line in the surface of the sample HAZL4 (see line a in Fig. 4). The equivalent stresses are plotted for the displacements: $\Delta u=0.1,1.0$ and $2.5 \mathrm{~mm}$, the latter corresponding to stress values slightly after the maximum load. The figure shows that, after plastic deformation in the HAZ zone, it spreads over the sample (see stress line for $\Delta u=1 \mathrm{~mm}$ ) and final strain localisation occurs in the adjacent materials when the stress exceeds the correspondent strength $\left(Y_{\max }^{\mathrm{ADJ}}=843 \mathrm{MPa}\right)$. Stress values in the HAZ are always above its critical value $\left(Y_{\max }^{\mathrm{HAZ}}=1029 \mathrm{MPa}\right)$.

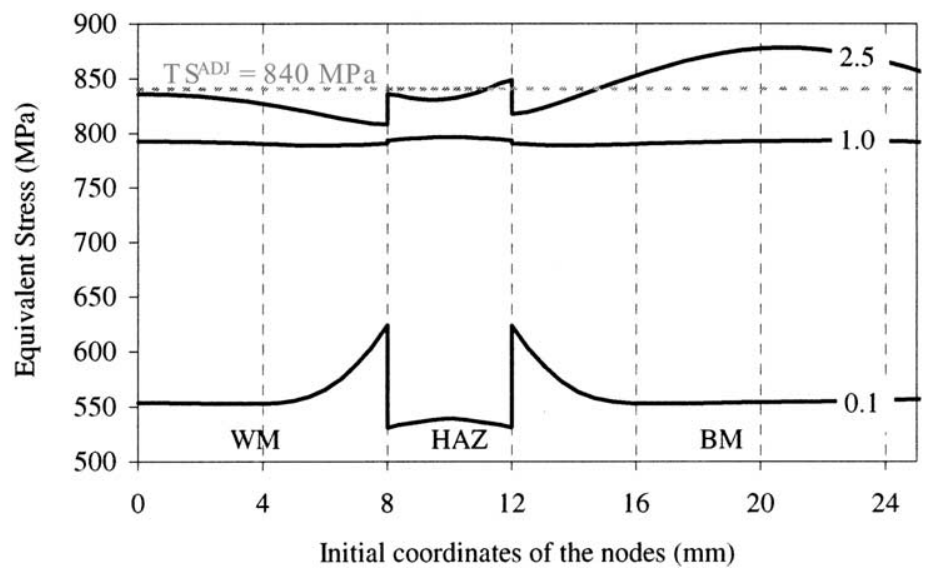

Fig. 6. Equivalent stress distribution along the $O x$ direction (line $a$ in Fig. 4) for a HAZL4 sample with overmatch tensile strength in the HAZ. Plotted values for three tensile displacements: $0.1,1.0$ and $2.5 \mathrm{~mm}$. 
According to Fig. 5, this type of behaviour is independent of the yield stress undermatch value, suggesting that the degree of tensile strength mismatch determines the overall strength of the sample. It is possible to confirm this by observing Fig. 7, where all the normalised load values are grouped together as a function of the tensile strength mismatch $\left(M_{\mathrm{TS}}\right)$. This graph shows that for all the HAZ widths, the maximum load in the samples increase almost linearly with increasing values of the tensile strength. When the overmatch values are reached the load capacity of the joint is equal to that of the homogeneous base plate.

For the cases with tensile strength evenmatch $\left(M_{\mathrm{TS}}=0.97,0.98,0.99\right)$, the reduction in maximum load values is not greater than $5 \%$ in most of the cases. The only exceptions are for large values of the $l_{\text {HAZ }}$ and severe yield stress undermatch (Fig. 5). In fact, the loss of strength with increasing $l_{\mathrm{HAZ}}$ values is a general tendency, which is more pronounced for the cases with high yield and tensile strength undermatch. Moreover, when the width of the HAZ is smaller then $1 / 3$ of the sample thickness $\left(l_{\mathrm{HAZ}}=1 \mathrm{~mm}\right)$, only a small decrease in the maximum load values is observed in all mismatch situations (Fig. 5). For the more pronounced case of yield and tensile strength undermatch $\left(Y_{0}=400 \mathrm{MPa}, n=0.08\right.$ with $M_{\mathrm{YS}}=0.57$, $\left.M_{\mathrm{TS}}=0.65\right)$, the strength of the joint is only $10 \%$ less than the homogeneous material.

Based on the data of Fig. 7, a relationship between the normalised load [ratio between the maximum load in a joint with undermatch HAZ material $\left(F_{\text {joint }}\right)$ and the base material strength $\left.\left(F_{\text {hom }}\right)\right]$, and tensile strength undermatch $\left(M_{\mathrm{TS}}\right)$, for each HAZ size $\left(l_{\mathrm{HAZ}} / e\right)$ can be fitted as follows:

$$
\frac{F_{\text {joint }}}{F_{\text {hom }}}=\left[\left(0.845\left(l_{\mathrm{HAZ}} / e\right)+0.066\right)\left(M_{\mathrm{TS}}-1\right)+1\right]
$$

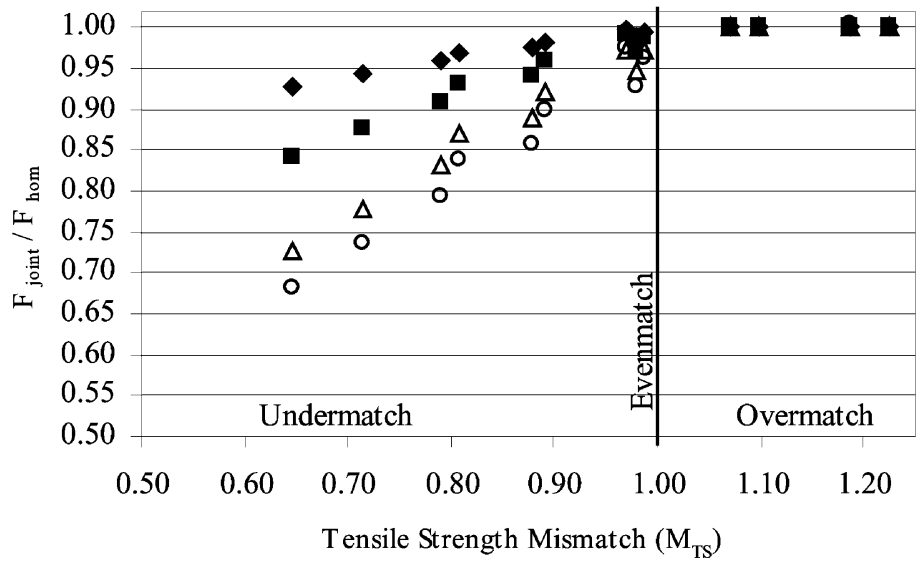

$$
\bullet / / e=1 / 6 \quad-/ / e=1 / 3 \quad \Delta / / e=2 / 3 \quad \circ / / e=1
$$

Fig. 7. Normalised load values $\left(F_{\text {joint }} / F_{\text {hom }}\right)$ as a function of the tensile strength mismatch $\left(M_{\mathrm{TS}}\right)$, for different ratios $\mathrm{HAZ}$ width to sample thickness $\left(l_{\mathrm{HAZ}} / e=1 / 6,1 / 3,2 / 3\right.$ and 1$)$. 
Values calculated with this equation have been compared with numerical and experimental results. In general, the maximum load attained by the joint can be predicted with a precision of $\pm 5 \%$.

The joint ductility is also analysed, by plotting in Fig. 8 , the ratio $\Delta l_{\text {joint }} / \Delta l_{\text {hom }}$ between the maximum elongation in the welded samples $\left(\Delta l_{\text {joint }}\right)$ and the elongation in a sample of homogeneous base plate $\left(\Delta l_{\text {hom }}\right)$. The results grouped in Fig. 8 , allows us to conclude that the mismatch in the material properties induce a decrease of ductility, which is more enhanced for low values of $M_{\mathrm{YS}}$. However, for each $M_{\mathrm{YS}}$ value, it is possible to observe an increase in ductility with the reduction in the HAZ width.

In order to get a better understanding of the ductility behaviour of the sample, and its relation to the material properties and the HAZ dimensions, the strain distribution along the sample (length $a$ in Fig. 4), at the maximum load, is plotted in Fig. 9, for various tensile strength mismatch levels of the HAZL6 and HAZL1 samples. From this figure, it can be seen that for the HAZL6 sample $\left(l_{\mathrm{HAZ}} / e=1\right)$, in the cases of evenmatch $\left(M_{\mathrm{TS}}=0.98\right)$ and undermatch $\left(M_{\mathrm{TS}}=0.65\right)$, the deformation is strongly localised inside the HAZ, and the strain values in the adjacent materials are very close to zero (excluding the materials interface). This clearly demonstrates that for $M_{\mathrm{TS}} \leqslant 1.0$ and $l_{\mathrm{HAZ}} / e=1$, the ductility of the overall sample strongly depends on the hardening behaviour of the HAZ. On the other hand, the same figure shows that for the samples with HAZ tensile strength overmatch $\left(M_{\mathrm{TS}}=1.10\right.$ and 1.19$)$, deformation spreads all over the sample presenting lower strain values in the HAZ. This explains the results in Fig. 8 where a loss of ductility is detected for the cases with overmatched tensile strength. For the small HAZ widths (HAZL1, lower graph in Fig. 9), the strain distribution in the HAZ is almost constant and the spreading of deformation explains the highest ductility values observed in Fig. 8 for these samples.

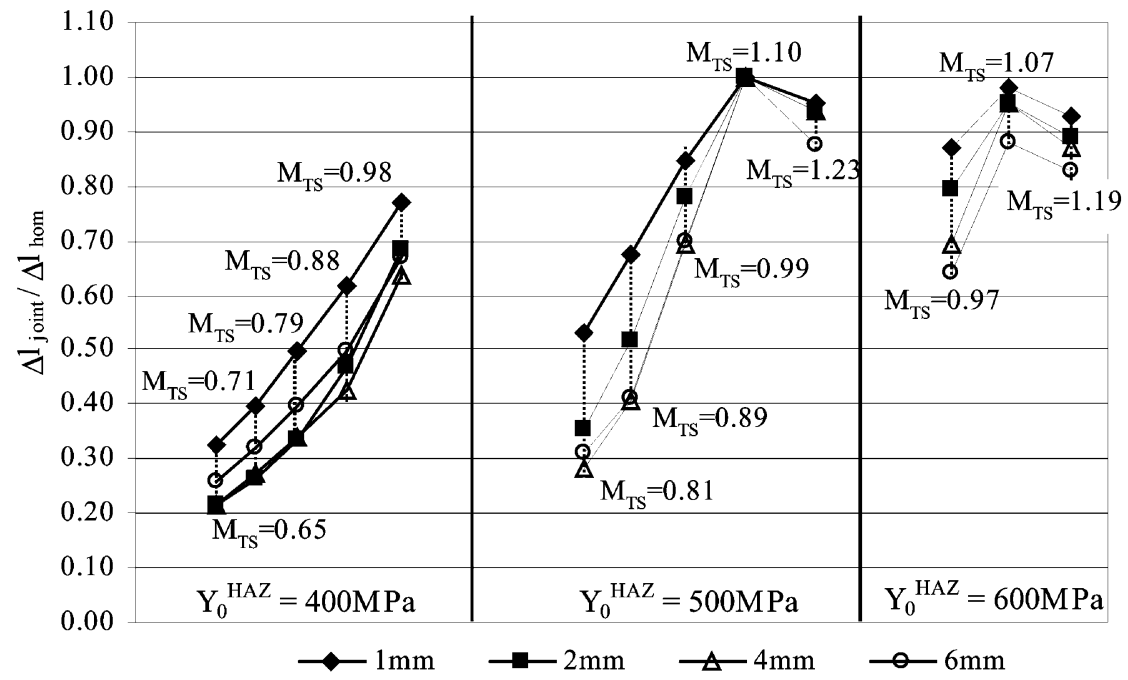

Fig. 8. Ductility defined as $\left(\Delta l_{\text {joint }} / \Delta l_{\text {hom }}\right)$ as a function of the tensile strength mismatch $\left(M_{\mathrm{TS}}\right)$, for different $\mathrm{HAZ}$ yield stresses $\left(Y_{0}^{\mathrm{HAZ}}=400,500\right.$ and $\left.600 \mathrm{MPa}\right)$ and $\mathrm{HAZ}$ widths $\left(l_{\mathrm{HAZ}}=1,2,4 \mathrm{and} 6 \mathrm{~mm}\right)$. 

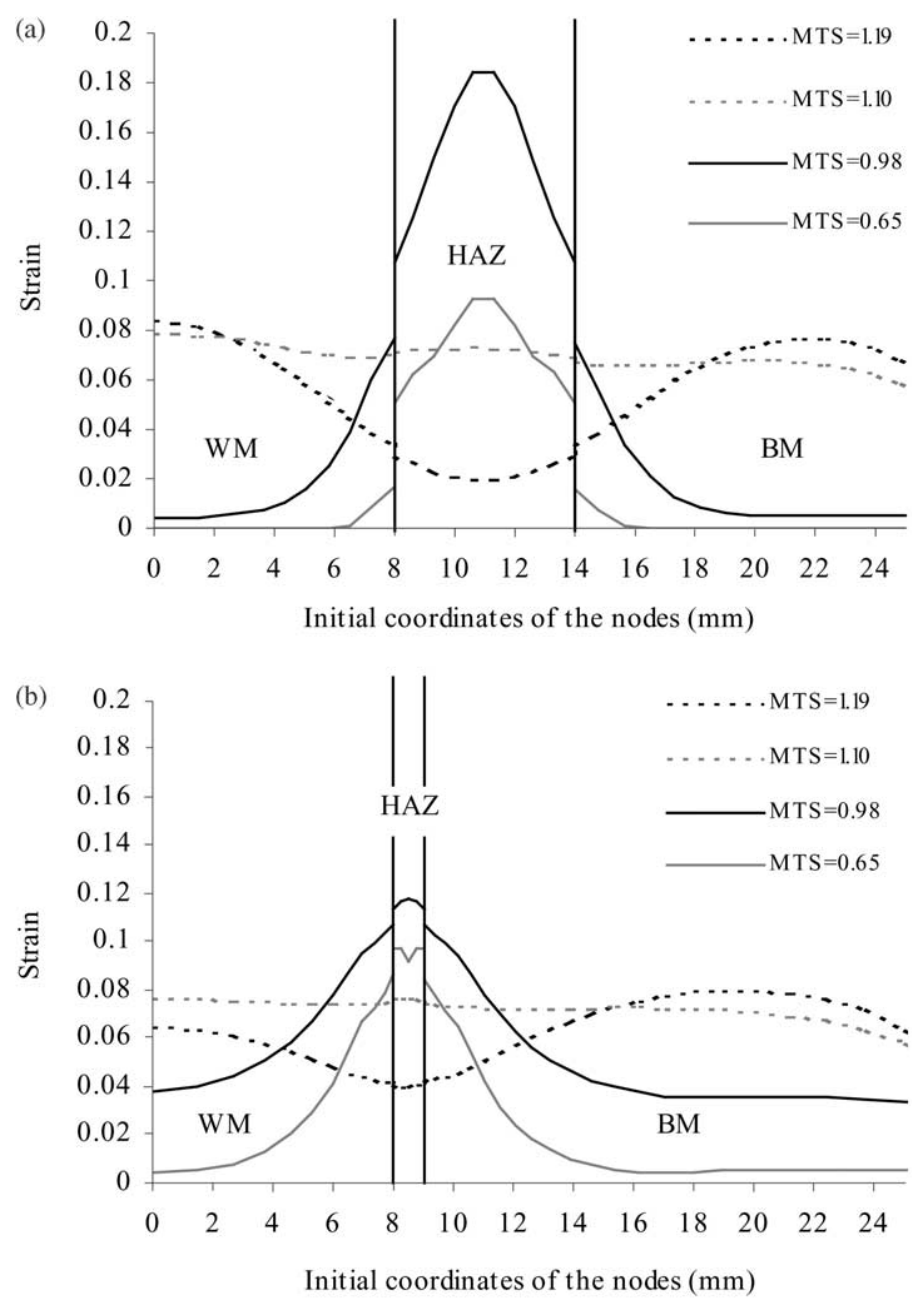

Fig. 9. Strain distribution along the samples HAZL6 and HAZL1 for various tensile strength mismatch $\left(M_{\mathrm{TS}}=0.65,0.98,1.10\right.$ and 1.19$)$.

From the results presented in Figs. 5 and 8 it is possible to conclude that much larger yield undermatching can be tolerated without loss of strength and ductility, when the HAZ material has high strain hardening coefficients (tensile strength even or overmatch). But, for each strain hardening value a clear effect of HAZ dimensions at the maximum load level can be observed.

\subsection{Study of the influence of constraint in the plastic behaviour of the $H A Z$}

When a butt weld is loaded in tension normal to the weld direction, as soon as yielding occurs, constraint is developed at the interface between the soft material 
and the adjacent materials that remain unyielded. This tends to prevent strain in the transverse direction and the soft material develops a hydrostatic stress component. Thus, relatively larger tensile stresses are required to further increase plastic strain in the soft material. It is possible to analyse the influence of constraint in the HAZ strength, calculating the strain energy absorbed by the HAZ material, until the maximum load is attained in the sample. The plastic strain energy per unit volume is given by the equation:

$$
W=\int \bar{\sigma} \mathrm{d} \bar{\varepsilon}^{\mathrm{p}}
$$

where $\bar{\sigma}$ is the equivalent stress and $\bar{\varepsilon}^{\mathrm{p}}$ is the equivalent plastic strain. Due to constraint, it can be assumed that the resulting strain energy in the constrained HAZ $\left(W^{\mathrm{c}}\right)$ can be decomposed into two components:

$$
W^{\mathrm{c}}=W^{\text {hom }}+W^{\text {het }}
$$

where $W^{\text {hom }}$ is the strain energy absorbed during the homogeneous deformation of an uniaxial tensile sample of the same material of the HAZ (this energy can be calculated knowing the mechanical properties of each HAZ material), and $W^{\text {het }}$ is a term associated with the presence of constraint. The strain energy that corresponds to $W^{c}$ can be directly computed from numerical simulations, at the integration points inside the domain that represents the HAZ. By applying Eq. (6) it is then possible to calculate $W^{\text {het }}$.

Figs. 10 and 11 show the ratio $W^{\text {het }} / W^{\text {hom }}$, as a function of the hardening coefficient and HAZ width. This ratio can be considered as a constraint factor that expresses the nature and magnitude of the constraint effects in the plastic behaviour of the HAZ. In these figures, positive values of the constraint factor when the maximum load in the overall joint is attained, imply that $W^{\mathrm{c}}>W^{\text {hom }}$. In these cases, the hydrostatic stress tensor induced by constraint increases the material strength in the HAZ.

Moreover, Figs. 10 and 11 shows in some cases, negative values of the constraint factor, indicating that $W^{\mathrm{c}}<W^{\text {hom }}$. In these cases, the maximum load of the sample occurs in the adjacent regions and the equivalent stress and strain values in the HAZ are lower than the maximum strength of this material. This occurs for materials with overmatch tensile strength (for the reasons exposed above, see example in Fig. 6), and also, in some cases of evenmatch and undermatch tensile strength. The study of the influence of constraint in the plastic behaviour of the HAZ is detailed, using, some examples in order to illustrate the conclusions that can be drawn from this study.

\subsection{Influence of the $H A Z$ dimensions in the constraint effects}

For various mismatch conditions, Fig. 10 shows positive (HAZL1 sample) and negative (HAZL6 sample) values of the constraint factor, indicating a strong influence of the size of the HAZ in the constraint effects. This can be better understood, by analysing the equivalent stress and stress in the thickness and width directions 


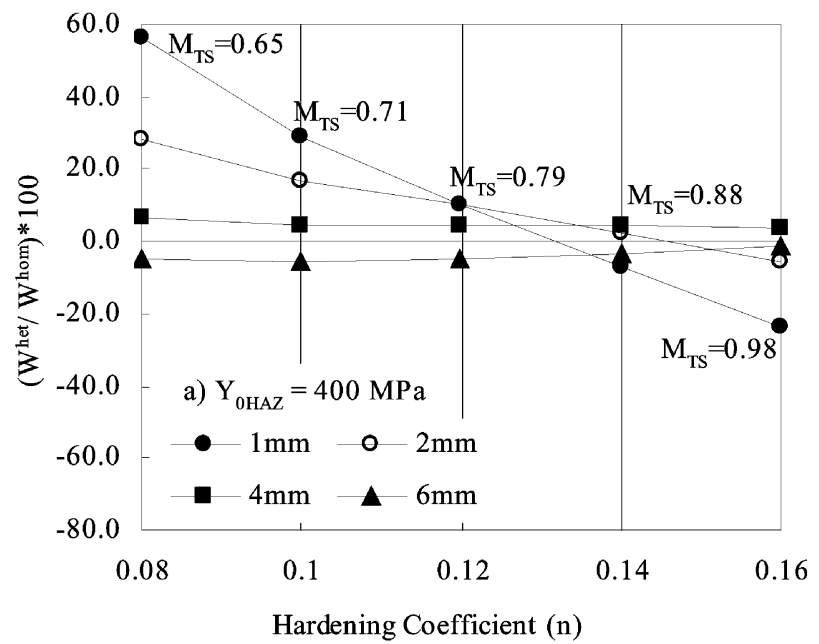

Fig. 10. Strain energy ratio ( $\left.W^{\text {het }} / W^{\text {hom }}\right)$ as a function of the hardening coefficient $(n)$, for HAZ widths equal to 1, 2, 4 and $6 \mathrm{~mm}$, in the case of a HAZ yield stress $\left(Y_{0}^{\mathrm{HAZ}}\right)$ equal to $400 \mathrm{MPa}$.

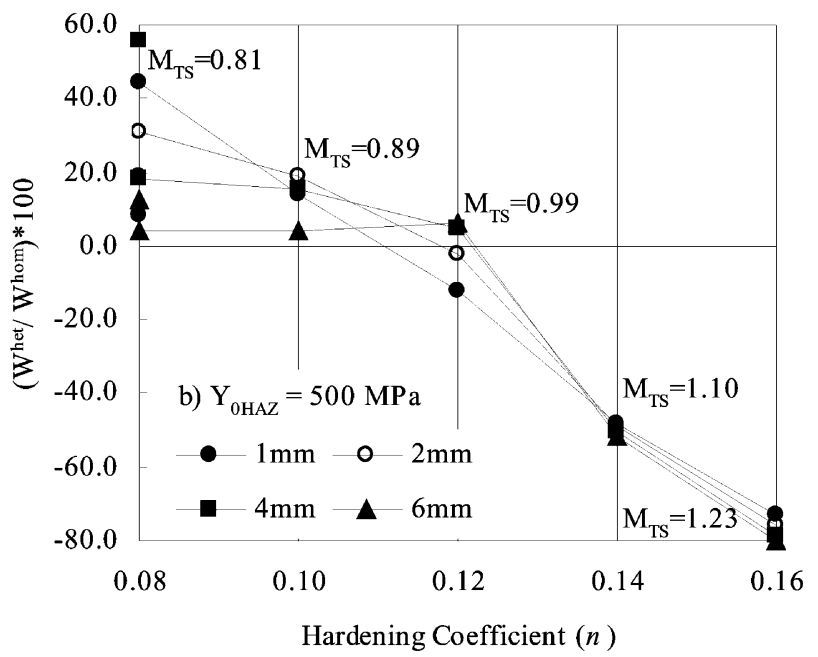

Fig. 11. Strain energy ratio ( $\left.W^{\text {het }} / W^{\text {hom }}\right)$ as a function of the hardening coefficient $(n)$, for HAZ widths equal to $1,2,4$ and $6 \mathrm{~mm}$, in the cases of a HAZ yield stress $\left(Y_{0}^{\mathrm{HAZ}}\right)$ equal to $500 \mathrm{MPa}$. For $n=0.08$, it is also shown the case of ( $Y_{0}^{\mathrm{HAZ}}$ ) equal to $600 \mathrm{MPa}$ (grey symbols).

( $\sigma_{y y}=\sigma_{z z}$ due to symmetry) plotted along a line in the HAZ of these samples (line $b$ in Fig. 4). This is carried out in Fig. 12, where the stress lines are plotted for different tensile displacements in samples with $\mathrm{HAZ}$ material $\left(Y_{0}=400 \mathrm{MPa}, M_{\mathrm{TS}}=0.65\right)$. The line with highest stress levels corresponds to stress values at the maximum load. Comparing the stress lines plotted in each graph, it is possible to understand the differences in the plastic deformation behaviour observed in Fig. 10. 
For the sample HAZL1, positive stresses in the thickness direction constraint the deformation in the HAZ (see strain curves in Fig. 9). This necking inhibition enhances the material strength (see equivalent stress values at maximum load in Fig. 12) resulting in a positive constraint factor. On the other hand, for the sample HAZL6, the stresses in the thickness directions are negative which lead to a decrease in the hydrostatic stress. The deformation in the thickness direction is now facilitated (Fig. 9) leading to premature necking in the HAZ and subsequent negative energy balance. In the case of $Y_{0}=500$ and $600 \mathrm{MPa}$ (Fig. 11), the constraint factor for the samples HAZL6 is now positive. This indicates that the negative effect of the constraint in strength for large HAZ widths vanishes with increasing yield stress in
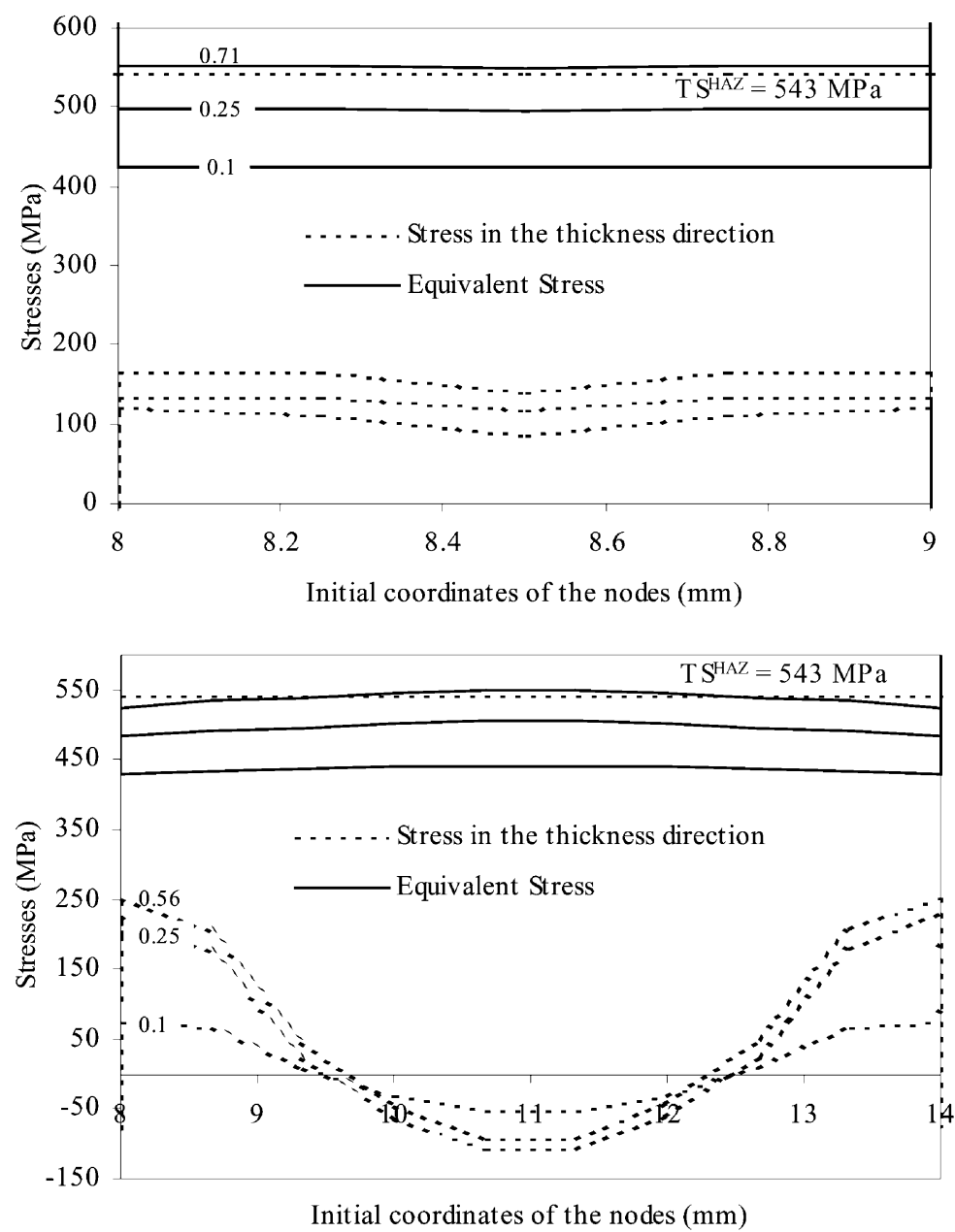

Fig. 12. Equivalent stress and stress in the thickness direction $\left(\sigma_{\mathrm{yy}}\right)$ in the HAZ (line $b$ in Fig. 4), at three elongation values, for the samples HAZL1 and HAZL6. Grey line corresponds to the maximum stress in a tensile test of a homogeneous sample of the HAZ material $\left(T S^{\mathrm{HAZ}}=543 \mathrm{MPa}\right)$. 
this region. In fact, for such high yield stress values, the stress distribution in the sample at the beginning of deformation is uniform, avoiding premature strain localisation in the HAZ.

\subsection{Influence of the mismatch in the constraint effects}

The results in Figs. 10 and 11 show that for increasing values of the hardening coefficient, the constraint factor can decrease drastically and become negative, for the samples HAZL1 and HAZL2. In Fig. 13 the equivalent stress lines along the
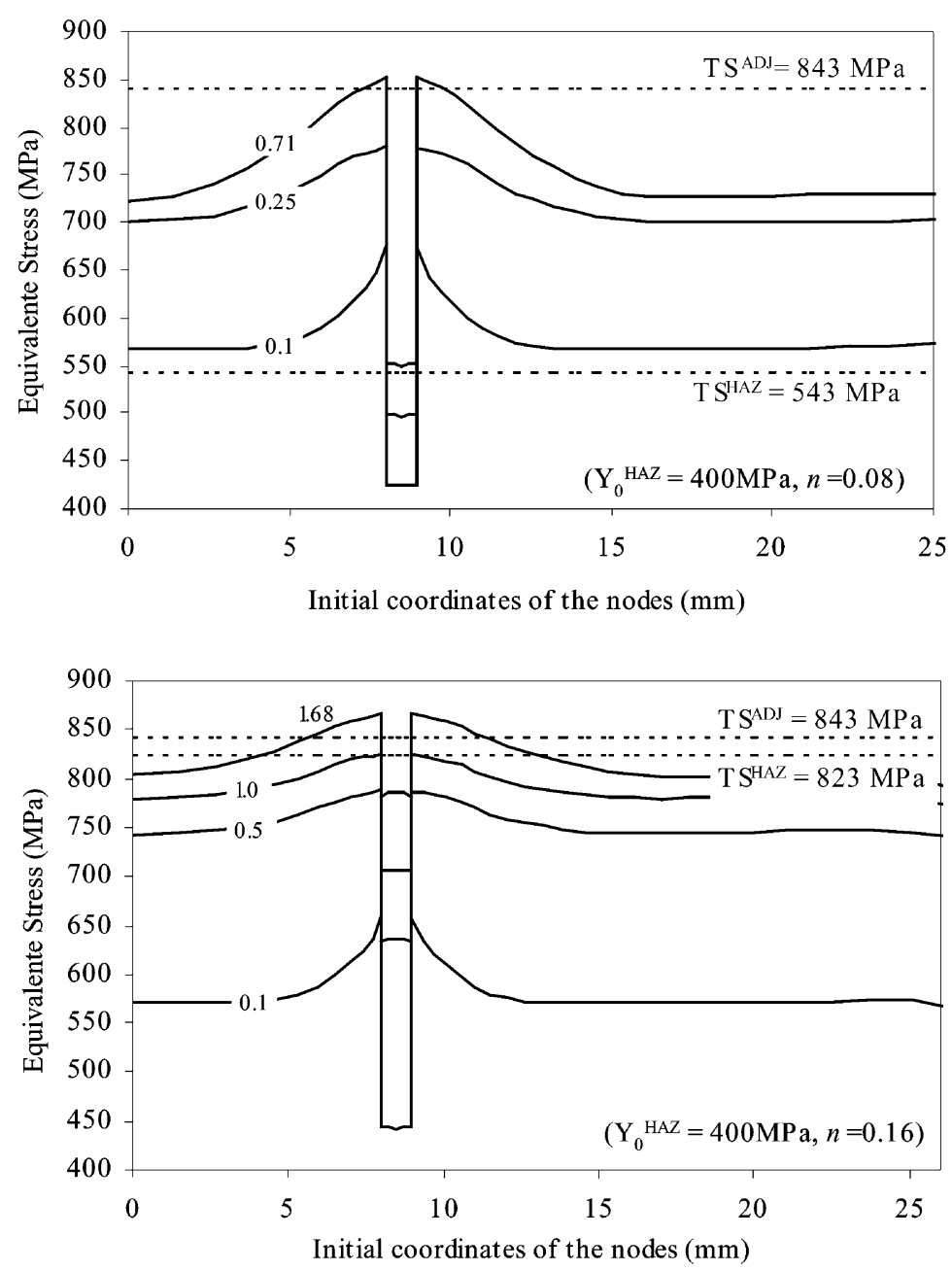

Fig. 13. Equivalent stress distribution along the $O x$ direction (line $a$ in Fig. 4) for a HAZL1 sample with different HAZ materials: $Y_{0}=400 \mathrm{MPa}, n=0.08$ and $Y_{0}=400 \mathrm{MPa}, n=0.16$. Grey lines correspond to the maximum stress in a tensile test of a homogeneous sample of the HAZ $\left(T S^{\mathrm{HAZ}}\right)$ and adjacent materials $\left(T S^{\mathrm{ADJ}}=843 \mathrm{MPa}\right)$. 
surface of the sample HAZL1 (line a in Fig. 4) with HAZ materials ( $Y_{0}=400 \mathrm{MPa}$, $n=0.08)$ and $\left(Y_{0}=400 \mathrm{MPa}, n=0.16\right)$ are shown. In the upper graph, which corresponds to a strong undermatch situation, it is possible to observe that for the maximum load the equivalent stress in the HAZ is larger than its maximum value (obtained in a tensile test with a homogeneous sample of the same HAZ material), whereas the stress values in the adjacent materials remain above their maximum value (obtained in a tensile test with a homogeneous sample of the adjacent material). In this case, the maximum load of the joint depends on the HAZ strength that is increased by constraint, leading to positive values of the constraint factor.

However, when the material of the HAZ presents tensile strength evenmatch, deformation spreads over the sample. In the lower graph of Fig. 13, it is possible to observe high stress values in the WM and BM, especially at the interfaces between the different materials. In this case, the maximum load of the joint will be determined by the adjacent materials plastic behaviour, the stress values attained in the HAZ being lower than their critical load. This explains the negative values obtained for the constraint factor.

\section{Conclusions}

In this paper, the mechanical behaviour of welded joints in high strength steels is discussed. The first conclusions concern the overall strength and ductility of the joint in relation to mismatch and HAZ dimensions. From the results it is possible to conclude that:

- The tensile strength of the soft zone determines the overall strength of the joint. In fact, independent to the level of the yield stress undermatch, the joints achieve the base plate strength in all tensile strength overmatch situations. For evenmatch and undermatch cases the strength of the joint is strongly dependent on the HAZ dimensions.

- For the cases in which the ratio width of the HAZ to sample thickness is less than $1 / 3$, the loss of strength never exceeds $10 \%$, even for cases of extreme strength undermatch. However, the joint strength decreases linearly with increasing HAZ widths.

- In almost all the cases, mismatch leads to a decrease in joint ductility, which varies depending on HAZ dimensions and hardening values.

In any case, the mechanical behaviour of the overall joint depends on the plastic distribution inside the HAZ. In fact, large tensile strength undermatch promotes strain localisation in the HAZ from the start of deformation, but for very small HAZ dimensions (width $<1 / 3$ of the thickness) the soft material can achieve the base plate strength. Depending on the tensile strength mismatch it can be stated that:

- In almost all the undermatch cases and for $l_{\mathrm{HAZ}} / e$ ratios lower than unity, an apparent increase in the material strength is observed due to constraint. 
- For the tensile strength evenmatch situations, the HAZ constraint induces spreading of deformation to the adjacent materials avoiding deformation in the soft HAZ material.

- Finally, for large yield stress undermatch and HAZ widths equal to the sample thickness, constraint promotes premature failure in the soft zone decreasing the overall strength of the joint even more.

\section{Acknowledgements}

The authors are indebted to FCT for financial support through Programa PRAXIS XXI.

\section{References}

Akselsen, O.M., Rørvik, G., Onsøien, M.I., Grong, Ø., 1989. Assessment and predictions of HAZ tensile properties of high-strength steels. Welding Journal 68, 356s-362s.

Cleveland, R.M., Ghosh, A.K., 2002. Inelastic effects on springback in metals. International Journal of Plasticity 18, 769-785.

Denys, R., 1994. Strength and performance characteristics of welded joints. In: Schwalbe, K.-H., Koçak, M. (Eds.), Mis-Matching of Welds, ESIS 17. Mechanical Engineering Publications, London, pp. 59102.

Dexter, R.J., 1997. Significance of strength undermatching of welds in structural behaviour. In: Schwalbe, K.-H., Koçak, M. (Eds.), Mis-Matching of Interfaces and Welds. GKSS Research Center Publications, Geesthacht, FRG, pp. 55-73.

Easterling, K., 1985. Introduction to the Physical Metallurgy of Welding. Butterworths \& Co (Publishers) Ltd, Borough Green, Sevenoaks, Kent TN158PH, England.

Fernandes, J.V., Rodrigues, D.M., Menezes, L.F., Vieira, M.F., 1998. A modified Swift Law for prestrained materials. International Journal of Plasticity 14, 537-550.

Goda, K., 2002. Creep-rupture lifetime simulation of unidirectional metal matrix composites with and without time-dependent fiber breakage. International Journal of Plasticity 18, 1729-1748.

Hiwatashi, S., Van Bael, A., Van Houtte, P., Teodosiu, C., 1998. Prediction of forming limits under strain-path changes: application of an anisotropic model based on texture and dislocation structure. International Journal of Plasticity 14, 647-669.

Kinsey, A.J., 2000. The welding of structural steels without preheat. Welding Journal 79, 79s-88s.

Li, S., Hoferlin, E., Van Bael, A., Van Houte, P., Teodosiu, C. (2003) Finite element modelling of plastic anisotropy induced by texture and strain-path change, International Journal of Plasticity (in press).

Marketz, W.T., Fischer, F.D., Clemens, H., 2003. Deformation mechanisms in TiAl intermetallicsexperiments and modelling, International Journal of Plasticity 19, 281-321.

Menezes, L.F., Teodosiu, C., Makinouchi, A., 1991. FE Simulation of 3D Sheet Metal Forming Process in Automotive Industry. 381-403.

Menezes, L.F., Fernandes, J.V., Rodrigues, D.M., 1999. Numerical simulation of tensile tests of prestrained sheets. Materials Science \& Engineering A264, 130-138.

Rapacki Jr., E.J., 1985. Plasticity of a high strength steel alloy. International Journal of Plasticity 1, 233242.

Rodrigues, D.M., Loureiro, A. and Menezes, L.F., 1999. Mechanical characterisation of the heat affected zone. In: Proc. 9th Meeting of Portuguese Materials Society, 21-23 June 1999, University of Minho, Vol. 2, pp. 339-344. 
Saraev, D., Schmauder, S., 2003. Finite element modelling of $\mathrm{Al} / \mathrm{SiC}_{\mathrm{p}}$ metal matrix composites with particles aligned in stripes - a 2D-3D comparison. International Journal of Plasticity (in press).

Soboyejo, W.O., Zhou, J., Crompton, J., McGaughy, T., Orth, F., 2001. An investigation of the fracture bahaviour of coarse-grained heat-affected zones in a 707 steel weld. Metallurgical and Materials Transactions 32A, 533-545.

Teodosiu, C., Hu, Z., 1995. Evolution of the intraganular microstructure at moderate and large strains: Modelling and computational significance. In: Shen, S.F., Dawson, P.R. (Eds.), Simulation of Materials Processing: Theory, Methods and Applications. Balkema, Rotterdam, pp. 173-182.

Thaulow, C., Paauw, A.J., Hauge, M., Toyoda, M., Minami, F., 1994. Fracture property of haz-notched weld joint with mechanical mis-matching-part II. In: Schwalbe, K.-H., Koçak, M. (Eds.), Mis-Matching of Welds, ESIS 17. Mechanical Engineering Publications, London, pp. 417-432.

Thaulow, C., Toyoda, M., 1997. Strength mis-match effect on fracture behaviour of HAZ. In: Schwalbe, K.-H., Koçak, M. (Eds.), Mis-Matching of Interfaces and Welds. GKSS Research Center Publications, Geesthacht, FRG, pp. 75-98.

Wojnowski, D., Oh, Y.K., Indacochea, J.E., 2000. Metallurgical assessment of the softened HAZ region during multipass welding. Journal of Manufacturing Science and Engineering (ASME) 122, 310-315.

Yoshida, F., Uemori, T., Fujiwara, K., 2002. Elastic-plastic behaviour of steel sheets under in-plane cyclic tension-compression at large strain. International Journal of Plasticity 18, 633-659. 